\title{
Microepithelial cysts observed in extended contact-lens wearing subjects
}

\author{
J. A. HUMPHREYS, J. R. LARKE, AND S. T. PARRISH \\ From the Department of Ophthalmic Optics, University of Aston, Birmingham
}

SUMMARY After 18 weeks of a controlled comparative study of extended contact lens wear a male subject presented with ocular symptoms. Microepithelial cysts were observed in both eyes and, after examination, in the eyes of 44 other participating patients. The cysts have been photographed and the rate of recovery monitored.

Microepithelial cysts have been reported in a number of ocular disorders ${ }^{1-3}$ and occasionally observed in differing types of contact lens wear. In a comparative controlled study, now reported, a high incidence of such cysts was encountered after approximately 6 months of extended soft contact lens wear.

\section{Material and methods}

A group of 75 Caucasian volunteers who came within a previously determined acceptance profile were randomly divided into 3 groups of 25 subjects each. Two groups were fitted with Sauflon PW lenses (Contact Lenses Manufacturing), while the third group remained unfitted with contact lenses and acted as controls. One group of subjects wore their contact lenses without removal and without recourse to proprietary cleaning agents. The second lens wearing group had their lenses removed at 4weekly intervals and cleaned with Monoclens C40 (Contact Lens Manufacturing). The subjects were examined at 2, 4, 6, and 8 days; 2, 3, and 4 weeks; and $2,3,4 \frac{1}{2}$, and 6 months, and a variety of subjective information and data were collected.

\section{Results}

At the eighteenth week of the study a male subject presented with symptoms of discomfort in the right eye. The conjunctiva was mildly congested and showed evidence of superficial epithelial disturbance in the lower nasal quadrant which stained with $2 \%$ sodium fluorescein. Visual acuity was reduced to $6 / 7.5$ from a previously corrected $6 / 5$. The contact lens previously worn on the eye was observed to be

Correspondence to Dr J. R. Larke, Department of Ophthalmic Optics, University of Aston, Gosta Green, Birmingham B4 7ET. damaged, and it was considered that the ocular signs and symptoms were consistent with the lens damage. However, on examining the eye a number of small, discrete, unstained epithelial cysts were observed in the lower portion of the cornea. After this observation 6 further subjects were examined and all showed the presence of similar bodies. As a consequence all further contact-lens wearing subjects were examined and a number of slit-lamp photomicrographs taken with the aid of a Holden/Zantos attachment to a Nikon Photo-Slip Lamp. Examples of the photographed appearance are shown in Figs. 1 and 2. Of 45 contact-lens wearing subjects 44 showed evidence of epithelial cysts, while the remaining subject developed cysts 2 weeks after contact lens wear had ceased. However, the severity of cysts varied, and for the purposes of the study the appearance of the cysts was ranked at 5 levels. Although the presence of cysts was not considered to be particularly serious, their presence in all subjects caused the study to be abandoned and lens wear was stopped. After lens removal the patients were monitored for recovery over the next 20 weeks. The ranked severity of cysts and recovery rate are tabulated in Table 1 .

\section{Discussion}

The widespread incidence of microepithelial cysts was an unexpected complication to extended soft contact-lens wear. Brown and Lobascher ${ }^{4}$ reported cysts to occur in aphakic subjects wearing Permalens. More recently Josephson ${ }^{5}$ has reported a single patient presenting with cysts from an unidentified form of extended contact-lens wear. The cysts in the present instance occurred in almost all subjects after approximately the same period of lens wear. With the exception of the first subject, who had a damaged lens, the patients were asymptomatic and 


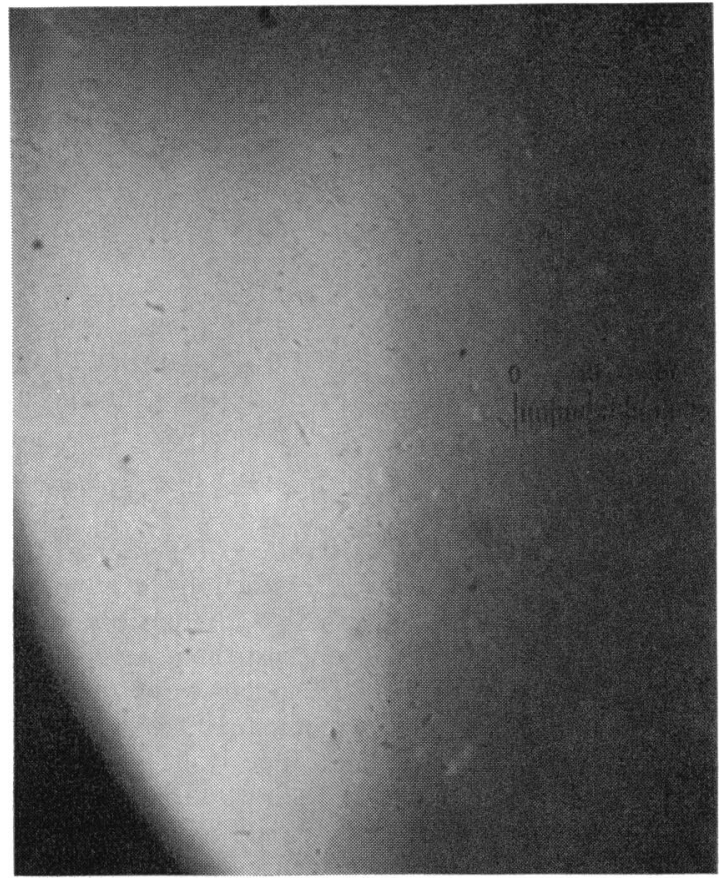

Fig. 1 Microepithelial cysts photographed with a

Holden/Zantos attachment on a Nikon photo slit-lamp. Ten scale divisions $=140 \mu \mathrm{m}$.

showed no other ocular signs. The cysts appeared to range in size between 10 and $90 \mu \mathrm{m}$ in diameter and were most easily viewed by retroillumination. The recovery time averaged 10 weeks and thus was considerably beyond the life cycle of individual epithelial cells, suggesting some form of attachment, possibly to Bowman's membrane.

The aetiology of microepithelial cysts in the cystic disorders has been well documented. ${ }^{6}$ ? In the present instance the cysts observed in extended contact-lens wearing patients, and in patients having Meesman's dystrophy, appear to have the closest clinical resemblance.

Of themselves the cysts may not be particularly serious. However, Ruben (personal communication) has suggested that a proportion may progress to

Table 1 Ranked severity of microepithelial cysts and recovery rate in weeks

\begin{tabular}{llllll}
\hline Ranked severity & 1 & 2 & 3 & 4 & 5 \\
\hline $\begin{array}{l}\text { Number of patients } \\
\begin{array}{l}\text { Average recovery time } \\
\text { (weeks) }\end{array}\end{array}$ & 33 & 9 & 2 & 1 & 0 \\
\hline
\end{tabular}

Ranking criteria. Area of cornea covered by cysts: (1) Up to $20 \%$ of total corneal surface, (2) $21 \%-40 \%$, (3) $41 \%-60 \%$, (4) $61 \%-80 \%$, (5) $>\mathbf{8 0} \%$.

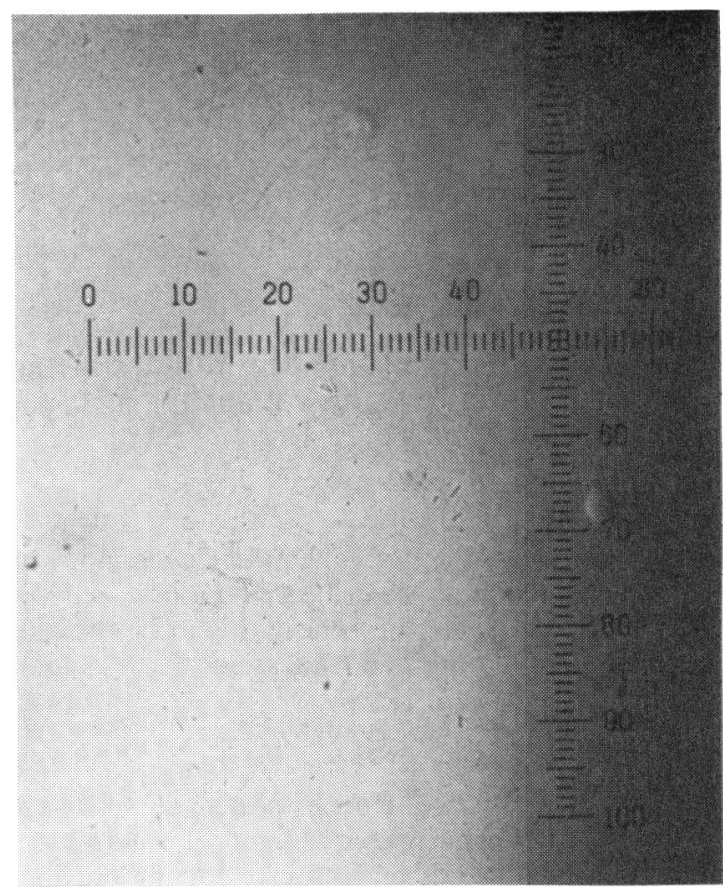

Fig. 2 Microepithelial cysts photographed with a Holden/Zantos attachment on a Nikon photo slit-lamp Ten scale divisions $=140 \mu \mathrm{m}$.

subepithelial fibrillar changes with eventual involvement of Bowman's membrane and corresponding reduction of vision, which would clearly be unacceptable in cosmetic contact-lens wear.

We acknowledge the support of the Medical Research Council and Contact Lenses Manufacturing in carrying out this work.

\section{References}

1 Graves B. Bilateral chronic affection of the endothelial face of the cornea of elderly persons with an account of the technical and clinical principles of its slit-lamp observation. Br J Ophthalmol 1924; 44: 502-44.

2 Cogan DC, Donaldson DD, Kuwabara T, Marshall D. Microcystic dystrophy of the corneal epithelium. Trans Am Ophthalmol Soc 1964; 62: 213-25.

3 McTigue JM. The human cornea: a light and electron microscopic study of the normal cornea and its alterations in various dystrophies. Trans Am Ophthalmol Soc 1967; 65: $690-60$.

4 Brown NA, Lobascher D. Complications of soft contact lens use in the correction of simple refractive errors. Proc $R$ Soc Med 1975; 68: 52-3.

5 Josephson J. Coalescing microcysts after long-term use of extended-wear lenses. Int Contact Lens Clin 1979; 16: 24.

6 Bron AJ, Tripathi RC. Cystic disorders of the corneal epithelium. I: Clinical aspects. Br J Ophthalmol 1973; 57: 361-75.

7 Tripathi RC, Bron AJ. Cystic disorders of the corneal epithelium. II : Pathogenesis. Br J Ophthalmol 1973; 57: 376-90. 